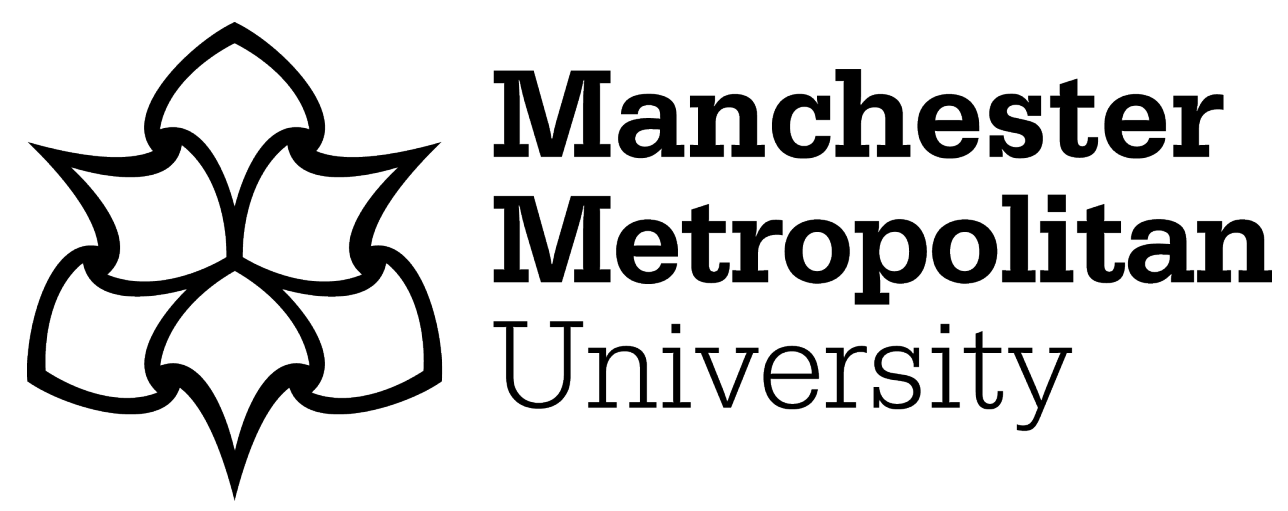

Grix, Jonathan and Houlihan, B (2014) Sports mega-events as part of a nation's soft power strategy: The cases of Germany (2006) and the UK (2012). British Journal of Politics and International Relations, 16 (4). pp. 572-596. ISSN 1369-1481

Downloaded from: https://e-space.mmu.ac.uk/621304/

Version: Accepted Version

Publisher: Sage

DOI: https://doi.org/10.1111/1467-856X.12017

Please cite the published version 


\section{Sports Mega-Events as Part of a Nation's Soft Power Strategy: The Cases of Germany (2006) and the UK (2012)}

This is a copy of the Author's Original Text of an article whose final and definitive form, the Version of Record, has been published in British Journal of Politics and International Relations [copyright Wiley], DOI: 10.1111/1467-856X.12017

To Cite: Grix, J. and Houlihan, B. (2014), Sports Mega-Events as Part of a Nation's Soft Power Strategy: The Cases of Germany (2006) and the UK (2012). The British Journal of Politics \& International Relations

Published Version Available At:

http://onlinelibrary.wiley.com/doi/10.1111/1467-856X.12017/abstract

The potential positive impact on a nation's image has moved from being a welcome consequence to a significant justification for investing in hosting sports mega-events. Mobilising Joseph Nye's concept of 'soft power' we empirically investigate Germany's strategic use of a sports 'mega' (the 2006 FIFA World Cup) to successfully alter their image among 'foreign publics'. We then analyse the example of the London 2012 Olympic and Paralympic Games for Britain's international prestige. For both cases we draw on and analyse official government documents and newspaper sources written before and after the Games. The findings reveal the stark contrast between Germany's and Britain's sport and 'soft power' strategies: the former undertook a long-term, well-planned and resourced approach to altering its poor international image; the latter appeared far less concerned about capitalising on the Olympics to enhance Britain's (seemingly robust) international image.

Keywords: Soft power; sports mega-events; international prestige

Research Highlights:

- The article discusses how states are increasingly using sports mega-events as part of their 'soft power' strategies

- The limited literature on 'soft power' and sports mega-events fails to either explain the concept and how it pertains to sport or provide examples that operationalize the concept empirically.

- Further research can build on the idea of sports mega-events being used for public diplomacy; the case of Germany, it could be argued, has led many 'emerging' states to seek to bid for and host such events.

- We show how the UK — with a very different international image to Germany prior to 2006engage in a different manner in its 'soft power' strategy.

- Finally, the macro-level concept of 'soft power' offers at least a partial answer to the unanswered question (in the sports studies literature) of why states host sports 'megas'.

\section{Introduction}

The last thirty years have witnessed the growing political salience of sport, especially elite sporting success and the hosting of mega sports events, to a wide range of governments of advanced and emerging economies. While a consensus regarding the definition of a 'mega-event' has yet to emerge there is 
substantial support (from Horne 2007, Matheson 2009 and Kellett et al. 2008) for Roche's definition that mega-events are 'large-scale, cultural (including commercial and sporting) events which have a dramatic character, mass popular appeal and international significance. They are typically organised by variable combinations of national governmental and international non-governmental organisations and thus can be said to be important elements in 'official' versions of public culture' $(1994,1)$. There is also agreement that, in relation to sport, only the Olympic Games and the footballWorld Cup qualify as mega-events with other events such as the cricket and rugby world cups and the European Champions League defined either as second tier, second order, major events, or as regional events (O'Brien and Gardiner 2006; Black 2008; Walters 2008). It is the 'international significance' of sports mega-events, the global captive audience and the involvement of government in their production as 'important elements in 'official' versions of public culture' that make them of interest in relation to the concepts of soft power and public diplomacy.

While investment in elite athlete development and in staging sports mega-events is generally justified with reference not only to the 'feelgood factor' ${ }^{1}$ that sporting success is said to bring to citizens, but also to the international prestige bestowed upon the nations which successful athletes represent, there has long been an acknowledgment of the beneficial impact of hosting a successful Olympic Games or football World Cup: on cities such as Calgary (Ritchie and Smith 1991); regions, such as Catalonia-Barcelona (Botella 1995); and nations, for example South Korea (Manzenreiter 2010). However, in more recent years the potential positive impact on the nation's image or brand has moved from being a welcome consequence to a significant justification for investing in hosting sports mega-events. One consequence is that many states have instrumentalised sport to promote their country's image (or, according to van Ham, their 'brand' $(2001,2)$ ) and gain prestige. 'Prestige' has long been recognised by scholars as an 'indispensable source of power' in international relations (Niebuhr cited in Kim 2004, 40), one which works alongside traditional 'material' forces of power such as military might and coercion.

Hosting a successful mega sports event and/or producing a successful squad of elite athletes is increasingly acknowledged to be a highly visible and potentially positive signal to other countries (Strenk 1979; Houlihan 1994; van Ham 2001). Such a strategy is also perceived by emerging economies as valuable in accelerating their entry to, and acceptance within, the world's mature economies. India's staging of the Commonwealth Games in 2010 and Brazil's hosting of both the 2014 FIFA World Cup and the 2016 Olympic and Paralympic Games could certainly be read as attempts by two rapidly expanding economies to announce that they had finally arrived on the international stage. More recently, small Gulf States, such as Qatar and Bahrain, have also become interested in staging sports mega-events with Qatar scheduled to host the 2022 football World Cup. ${ }^{2}$

It is against this background of increasing governmental intervention in, and the increasing political salience and commodification of, elite sport policy in domestic and international relations that we investigate the cases of Germany and the staging of the 2006 football World Cup and the London 2012 Olympic Games. ${ }^{3}$ The 2006 World Cup is generally considered to be one of the most successful recent uses of elite sport to improve a nation's image abroad (Anholt-GfK Roper 2007). Germany's strategic use of sport would, arguably at least, fit with Nye's concept of soft power and the pursuit of international recognition and prestige (Nye 1990, 2004), a strategy that is well documented (Hart-Davis 1986; Schiller and Young 2009; Dennis and Grix 2012). It is the external perception of prestige or 'national reputation' that Wang $(2006,92)$ believes is one of the clearer indications of a nation's power.

The aim of the article is to examine the utility of the concept of soft power in relation to Germany's hosting of the 2006 World Cup and the UK's hosting of the 2012 Olympic Games. The article begins with the exploration of the concept of soft power and the related concepts of (new) 'public diplomacy'

\footnotetext{
${ }^{1}$ The concept of a 'feelgood factor' is frequently deployed but is difficult to define and measure with precision. Cornelissen and Maennig (2010) review the attempts at definition and argue that the concept has three inter-related aspects: economic i.e. a willingness to pay to attend mega-sports events; socio-cultural - heightened brand or team loyalty; and political -, e.g. enhanced national unity and pride.

2 See Time online 'Sports as diplomacy: How small Gulf countries use big sports to gain global influence', at http://www.time.com/time/world/article/0,8599,2080062,00.html\%20, accessed 9 February 2012.

${ }^{3}$ See Gray 2007 for a discussion on the commodification of policy and its instrumental use by governments.
} 
and 'international prestige'. Secondly, we present two empirical case studies through the conceptual lens of 'soft power' and assess the extent to which mega-events can be effective in leveraging international prestige. Our German case rests on a systematic investigation of official (German) documentation relating to the FIFA World Cup in 2006, in addition to interviews with eight key actors and experts with knowledge of the event, the key factors behind its success and its meaning for Germany on the international stage. Data for the UK case has been obtained from an analysis of a range of government and Parliamentary documents published since 2006 augmented by an analysis of newspaper reports from a sample of international press published in the months prior to the start of the Games and in the weeks immediately following the closing ceremony (see Appendix 1 for more detail).

\section{Sport and the Study of International Relations}

As recently as 2004 Levermore and Budd $(2004,7)$ noted the 'poverty in IR of a serious analysis of sport' from the extant literature on and around the topic of the significance of sport to international relations. The following year Allison and Monnington (2005) lamented the continuing neglect of sport within the study of international relations. While the claim of relative neglect is still justified there have been signs in recent years of a growing interest in the role of sport in international relations (see for example, Jackson and Haigh 2009; Merkel 2008; L'Etang 2009; Ndlovu 2010; Berg et al. 2012). This modest increase in academic interest notwithstanding the relative lack of analysis of sport by political scientists and international relations scholars is surprising given that sport as a political resource has a long history both externally in inter-state relations, and internally, inter alia, as part of an attempt to create a sense of statehood among citizens. As Roger Levermore observes elite athletes or teams usually represent a 'nation' in non-domestic competition and the national team is often equated with the nation; given that much of the understanding of international relations is focused on the unit of analysis of the state, it is clear to see the potential of analysing and understanding elite sport (Levermore 2004, 8-9). Avery Brundage (President of the International Olympic Committee, 1952-1972), a very political figure in the world of sports politics himself, was adamant that sport and politics should not mix when he stated that 'sport ... like music and the other fine arts, transcends politics .... We are concerned with sports, not politics and business' (IOC 1968, 10). Unfortunately, Brundage's view does not hold up in the light of a history of 'coercive diplomacy' (Hill, cited in Levermore and Budd 2004, 3), including politically-driven boycotts (for example, the Moscow and Los Angeles Olympics), murder (Munich Olympics), and sports events mirroring political struggles (for example, Hungary vs. the USSR in Water Polo, 1956) (Strenk 1979). These examples do tend to fall into the realist paradigm with their focus on the military and security issues. Staging sports mega-events, as we shall see, is, however, more and more about projecting (soft) power and achieving foreign policy goals using non-material means.

Despite these and myriad other examples of the political instrumentalisation of sport and sporting events, international relations and sport still suffer from a 'case of mutual neglect' (Taylor 1986). Irrespective of the neglect of academics it is clear that a wide range of states-advanced capitalist, (consumer) communist and developing countries-view sporting prowess, and in particular the Olympic medal table, as a barometer of their standing not only in the sporting world, but also in the wider international community (Hilvoorde et al. 2010). ${ }^{4}$

\section{Introducing 'Soft Power', (New) Public Diplomacy and International Prestige}

Part of the reason behind the neglect of sport within the study of IR, Allison believes, is the fact that sport has generally fallen outside the purview of 'realism' and 'idealism', the 'established' approaches in the discipline $(2005,7)$. The concept of 'soft power', coined by Joseph Nye in the late 1980s, offers a lens through which to understand one of the increasingly important motivations for states to invest in elite

\footnotetext{
4 Interestingly, the IOC tried to prevent the publication of the medal table as early as 1921, recognizing its 'nationalistic' potential, see Guttman 2002,43 .
} 
sport-and the staging of sports mega-events—and what they seek to achieve through such an investment (Nye 1990). For Nye the changing nature of international relations after the end of the Cold War, and the risk attached to deploying traditional military forms of power, has led to 'intangible power resources such as culture, ideology, and institutions' becoming more important in inter-state relations (Nye 1990, 167). This should not be taken, however, to mean that Nye advocates replacing traditional 'hard power' with 'soft power' in international relations, but rather that states ought to make far more use of the latter; preferably in combination with the former (so-called 'smart power'; Nye 2004, 32). Nye defines power in terms of the ability to 'influence the behaviour of others to get the outcomes one wants' and sees soft power, the ability to 'attract and co-opt them to want what you want', as an alternative or complement to the exercise of hard power. (Nye 2004, 2). The essence of soft power is the ability to shape the preferences of others, and align those preferences to your own and as such is similar to Lukes' 'third dimension' of power, 'the power to shape, influence or determine others' beliefs and desires, thereby securing their compliance' $(2007,90)$ and also to the Habermasian notion of legitimation in relation to explanations of domination within democracies (Habermas 1979). The sources drawn upon by a state to exert such soft power are very different to those of traditional 'hard' power. Nye puts forward threes key sources of soft power: a state's culture, its political values and its foreign policy (Nye 2004, 11; Nye 2008, 96). ${ }^{5}$ Although a state's foreign policy is generally firmly under the control of the government and as such would suggest that soft power is best understood from the application of a realist perspective the other two elements of soft power-culture and political values-are much more likely to be coproductions between the state and institutions of civil society. In relation to sports mega-events while the state plays a central role the symbolism of the Olympic Games or the World Cup is strongly influenced by powerful non-state domestic and international actors such as national Olympic committees, national governing bodies of sport, international federations, the IOC and the national and international media. As Bially Mattern $(2007,102)$ comments 'Soft power may also appeal to individuals and collective non-state actors since, in contrast to hard power, which the government controls through military and economic policies, soft power is available to any actor that can render itself attractive to another'. The significant role of non-state actors in the production and deployment of soft power resources suggests that a liberal perspective would be the most appropriate for the analysis of the two cases.

(Elite) sport, as a cultural phenomenon can be utilised by governments in the pursuit of both domestic and international policy objectives. Domestically, states have used sport to bind individuals around collective, national experiences of sporting success and engender both a 'feelgood factor' and a cohesive identity akin to Benedict Anderson's 'imagined communities' (Anderson 1983; see also Tomlinson and Young 2006; Amara 2011). There is also strong evidence of the utilisation of sport in connection with foreign policy objectives by a wide variety of countries (see for example Manzenreiter 2010; Merkel 2008; Sport in Society 2008). The evidence suggests that international sporting success, whether by national teams and athletes competing abroad or by the effective staging of a sports mega-event, provides arenas for deployment of soft power through which states seek to 'attract' others with their values and culture and persuade them to want what they want by projecting a specific 'image' to foreign publics and by creating 'a favourable impression and increase[ing] understanding among foreign audiences' (Potter 2009, 51). For example, for Australia the national image projected before, during and after the Sydney Olympics in 2000 was one of a 'sporting nation'. According to the Australian Tourist Commission the result of a successful Olympics and the boost to their national image was the 'accelerated development of Brand Australia by 10 years' (Australian Tourist Commission 2001, 3; see Manzenreiter 2010 for China's use of the Beijing Olympics and image management). This 'image management', as we discuss below, is important if soft power is to be leveraged to shape international relations through affecting external perceptions of a country, although, it must be stated at this stage, that a country's 'image' must rest on something recognisable (e.g. a reputation for producing reliable products) other than simply good public relations (see also Anholt-GfK Roper 2010). Elite sport performance and the staging of sports mega-events are seen as two potential sources of international prestige. It is in large part the desire for international prestige that led Brazil to successfully bid to stage the world's two largest mega sporting events in close succession (FIFA World Cup, 2014; Olympic Games, 2016) as the country sees itself as an emerging

\footnotetext{
${ }^{5}$ Justin Morris lists the English language, Greenwich Mean Time, the 'Westminster Model' of government, English Law and the BBC World Service among other 'soft power' assets belonging to Britain. See Morris 2011, 332-3.
} 
power, along with other BRIC countries (Russia, India and China) and events like these offer a 'coming out party' in which countries are guaranteed a global audience for their 'brand' (Kuper 2011).

Sport has been used as a soft power resource in a number of different diplomatic contexts. For example, the oft quoted 'ping-pong' diplomacy of the 1970s can be read as an 'ice-breaker' role for sport, in which initial sporting contacts between the USA and China led on to more formal discussions and negotiations, following a basketball competition between the two countries one year later. The fact that the Chinese were clearly superior in table tennis, and the USA clearly superior in basketball, was designed to rob sport temporarily of one of its core attractions-its unpredictability. There is a difference between sport diplomacy and using sporting success to garner international prestige or to increase inward (foreign) investment and boost the tourist sector. It is clear that different states will have different reasons to draw on and use soft power and will also aim at different audiences. The USA is increasingly trying to win over the 'hearts and minds' of foreign publics, as well as opinion leaders, as an alternative to direct military intervention, and increasingly so after their image abroad was effected negatively following the Iraq war in 2003 (Grix and Himpler 2007). Those states burdened with negative national images and national stereotypes that impact on others' perception of them deriving from, inter alia, particular historical events, human rights issues, or poverty - for example, the Holocaust and the Germans—appear to have much more to gain from mobilising soft power to (positively) change their image. The governments of Germany, South Africa (2010 FIFA World Cup); China (2008 Olympic Games), India (2010 Commonwealth Games) and, in the future, Qatar (2022 FIFA World Cup) are, and will be, attempting to use sports mega-events to persuade the governments, businesses and the public in other countries to alter the often negative stereotypes they hold. Such is the interest in utilising the resource of soft power that Kurlantzick went as far as to say that 'China's growing soft power has emerged as the most potent weapon in Beijing's foreign policy arsenal' $(2007,5)$.

Public diplomacy, which, since 9/11 2001, has grown in importance among the majority of states throughout the world, is an instrument governments use to mobilize .... [soft power] resources to communicate with and attract the publics of other countries' (Nye 2008, 95). ${ }^{6}$ Public diplomacy studies differentiate between the 'old' modus operandi via 'hierarchical state-centric structures' on the one hand and the 'new' model of a 'network environment' in which several actors, of which the state is but one, undertake public diplomacy (Melissen 2005, 12; Hocking 2005, 72). However, the state, usually the Foreign Ministry, still plays a central role managing the network and funds many of the 'arm's length' organisations that make it up. This mirrors debates in political science literature on 'governance'. Governance scholars have highlighted a shift from big government to governance by and through networks; this can be seen in the trend to 'agencification', including arm's length agencies, the rapid growth of 'partnerships', networks, charities, advisory bodies, boards, commissions, councils and other para-statal bodies involved in policy deliberation and delivery (Bevir and Rhodes 2006; Marsh 2008a,b). The 'new' public diplomacy (see Signitzer and Coombs 1992) is consequently seen as involving an array of non-state actors including sporting bodies such as FIFA and the IOC (International Olympic Committee) at the international level and National Governing Bodies of sport (NGBs) at the national level. Both the IOC and FIFA are not beholden to national governments and cannot be 'controlled' and 'managed' in the same manner as those dependent on state resources, such as NGBs. It is not only the number of transnational contacts made through such non-governmental bodies, but also their number that is increasing (see also Nye 2004, 90). Drill down still further and we have 'image management' as a key strand of a state's public diplomacy. Increasingly, a state's 'image' or 'brand' is becoming a key asset in the international arena (van Ham 2001 even speaks of a 'brand state'), a topic that has produced its own branch of literature and leading 'experts' (Anholt-GfK Roper 2007, 2010; Potter 2009; Hocking 2005; Olins 1999; van Ham 2001). The main difference between what has been termed 'nation branding' and the more traditional 'public diplomacy' is that the former is about projecting a country's identity outwards and does so adopting a much more holistic approach than public diplomacy (Melissen 2005, 20-21). Public diplomacy, of course, uses traditional diplomatic channels and is generally understood as a tool for securing foreign policy interests, whereas 'branding' has turned to the tools of marketing to project a

\footnotetext{
6 As with the concept of soft power the concept of public diplomacy is contested and there are a number of competing definitions some of which (Signitzer and Coombs 1992 for example) give greater emphasis to the role of private individuals and groups in the practice of public diplomacy. See Gilboa 2008 for a fuller discussion.
} 
state's image abroad. Interestingly, in interviews with the German Foreign Office and in documents relating to the London Olympics, 2012, written by the Foreign Commonwealth Office, there appears some overlap of the 'old' and 'new' types of public diplomacy, blurring the role of the state in public diplomacy and branding. For example, both the UK and Germany appear to have unquestionably taken on the language of 'soft power'. They are equally at ease with the use of such marketing-related terms as 'nation branding' and national 'image'. For example, in Germany specific government-funded arm's length organisations were given responsibility for the 'branding' of Germany's hosting of the World Cup, an aspect which the Federal Government emphasised in their final report on the event in 2006. While the lines between 'nation branding' and 'public diplomacy' are less clear cut than perhaps they were previously, the central role of the state in manipulating sport to achieve non-sporting goals is apparent in both our case studies.

Sport, clearly, is seen to contribute to a state's 'brand' or 'image' by virtue of its 'nation building' qualities, that is, engendering domestic pride in a national team's achievements and by projecting a particular identity on the international stage that is attractive to others (see Maguire et al. 2002, 151-156 on sport and nationalism). Sport also works on another level as part of the 'cultural' sources of a state's soft power, along with broader cultural exchange (knowledge, language, art) between countries. Sports mega-events are successful in attracting the attention of billions of people across the globe and are hence a perfect platform to showcase the hosting nation, their culture and 'image' (Potter 2009, 92; see also Lin et al. 2008 , 28). This is deemed necessary, as continuing globalisation and the technologically-driven information revolution make it more important for states to differentiate themselves from others (van Ham 2001, 3; Nye 2008, 99) even if, ironically, states use increasingly similar strategies (for example, membership of international organisations and participation in, and the staging of, the Olympic Games and football World Cup) to demonstrate their distinctiveness. The resultant international prestige garnered from successfully hosting such an event or having one's national team perform well-or preferably both — can be converted into enhanced soft power that can make a state, their culture and political values more attractive to others. How enhanced prestige benefits the state's deployment of 'soft power' and how the process of attraction operates are not made entirely clear in Nye's writings (see Bially Mattern 2007), but in successful cases—and Germany's hosting of the 2006 World Cup is, we believe, one such example - the result can be an increase in the self-belief of the political elite, a reinvigoration of patriotism (effectively cornerstones of a national identity) among the general public, an increase in tourist visits to the host nation and a growth in inward investment and exports.

\section{Germany, Sport and Soft Power: The 2006 Football World Cup}

Germany has played a particularly central role in the political use of sport by states as part of their public diplomacy strategies. The 20th century provided key examples in the manipulation of elite sport by two German dictatorships, the Nazis and the communist-socialist East Germany. The Nazi Olympics of 1936 is widely recognised as the first and most blatant use of (elite) sport for political purposes and for attempting to showcase a country's—and regime's—image abroad (Senn 1999; Guttmann 2002; Hilton 2008). Equally, the second German dictatorship (the German Democratic Republic) is generally looked upon as the quintessential example of a state instrumentalising sport to achieve international recognition and legitimacy. East German sport representatives were dubbed 'diplomats in tracksuits' by the GDR leadership, because of their contribution to breaking the diplomatic deadlock and isolation of their country (Holzweissig 1981; Dennis 1988, 71).

\section{Germany's Staging of the 2006 FIFA World Cup}

This section examines the official FIFA rhetoric that proclaimed the German event 'the best World Cup of all time' (German Federal Ministry of the Interior [hereafter, FMI] 2006, 14) and analyses how Germany was able to use the World Cup as a public diplomacy tool to improve the generally negative external image of the country. Prior to the World Cup, according to Grix and Lacroix, to: 
.... suggest that Germany has an image problem abroad would not be new. It remains the case that the legacy of the Third Reich, the barbarity of the Nazis and the bellicose behaviour in the early part of the 20th century has etched itself deep into the psyche of Germans themselves and that of their international partners. Germany's rich cultural history and her spectacular rise from ruins during the post-war period rarely figure in foreigners' perception of modern-day Germany, especially it seems in Britain (Grix and Lacroix 2006, 373).

Given Germany's traumatic past, it had, arguably, the most to gain from attempting to forge a national image that 'has remained fixed in the stereotypes established in two world wars' (Watts 1965).7

Much of post-war Germany's identity has been built around the export-driven 'German model' based on a successful (social) democratic economic model which had 'won Europe's hearts and minds' (Markovits and Reich 1991, 11) because of its consistent economic performance and its social underpinnings. Postwar Germany was characterised by its lack of 'hard' power, a strong commitment to multi-lateral institutional arrangements, the expanding European Union and consistent efforts to convince foreign elites and publics alike that it had changed. 'Soft power' resources, in the shape of academic and cultural exchanges, have been the subject of heavy investment with the purpose of changing Germany's negative image abroad. Such organisations as the German Academic Exchange Service and the Goethe Institute (receiving around 200 million Euros per year; Interview German Foreign Office); have set up cultural centres and undertaken campaigns throughout the world and act as ambassadors for German culture and language (DAAD 2011; Goethe Institute 2011). ${ }^{8}$

Some glimmers of a growing national confidence through sport among the Germans were visible as early as 1954 when their team unexpectedly won the FIFA football World Cup. The 1972 Munich Olympics, on the other hand, was overshadowed by the tragic killing of 11 Israeli athletes and coaches by a Palestinian terrorist group. The only other major event to impact on Germany's international image and to touch on the sense of Germans' national pride was the collapse of the Berlin Wall in 1989 and the subsequent unification of East and West Germany in 1990.

In 2006 the world witnessed a spontaneous outpouring of (sport) patriotism which was in sharp contrast to how national feelings had been viewed in Germany previously (see also Kersting 2007, 291). This new reassertion of national pride drew on the tried and tested paraphernalia of old: flags and colours of the nation. Witnessed by a cumulative global TV audience of over 26 billion (FIFA 2011), the World Cup drew in two million foreign visitors to Germany (German Tourist Board 2007a). Aggregate attendance at matches was 98\% capacity (on average some 52,500; see FIFA 2012) and over 20 million people joined in the party-like celebrations around the unique public 'Fan Fests' with their large viewing screens set up in the 12 host cities in Germany (German Tourist Board 2007a, 8; Florek et al. 2008, 202). This sports mega-event offered the most powerful platform to showcase German people and culture.

\section{Indicators of Success}

Given that most predictions of the benefits of sport mega events are usually overstated (Horne and Manzenreiter 2006) the identification of valid indices of success is important. Despite the difficulty in defining the concept of soft power and measuring its impact, some tangible data do exist to indicate that the German 2006 staging of the FIFAWorld Cup was successful. First, tourism was and continues-six years after the event - to be one of the biggest beneficiaries of theWorld Cup (along with the airline, food, film and media industries in 2006; Federal Government 2006a, 23; Federal Government Online 2006). Over two million foreign visitors came to Germany for the football in 2006 (many stayed on and visited tourist attractions) and the Board recorded a bumper year of overnight stays by international visitors, which increased further by $3.5 \%$ in 2007 (up to 55 million stays), despite the fact there was no major event in Germany in that year (German Tourist Board 2007b, 11). Interestingly, Britain, where a

\footnotetext{
${ }^{7}$ Watts is referring to British attitudes towards the Germans, but many other nations shared this view.

8 The current article has benefitted from DAAD funding for fieldwork in Berlin in the summer of 2011.
} 
negative image of Germany is most deeply entrenched, recorded the largest increase in visitors from all nations (up 5\% from 2005 to 2007, totalling 4.4 million overnight stays; German Tourist Board 2007b, 12). ${ }^{9}$ A further indicator of the effect of 2006 on Germany's image is provided by the Anholt-GfK Roper Nation Brands Index, which measures a nation's standing among people around the world through a representative survey of non-German nationals (Anholt-GfK Roper 2011). Germany went from seventh in 2004 to first in 2007 on this list and remained in second place in 2011 (Anholt-GfK Roper 2011). Finally, interview partners spoke of a new 'easiness' (Leichtigkeit) with which the Germans dealt with their identity, a sentiment not witnessed in post-war Germany (e.g. Interviews 3 and 5). The majority of the interviewees believed that the World Cup effect on the German self-image continues to this day, the significance of which is discussed in the next section.

\section{Key Factors Behind Germany's Success}

The research revealed that what lies behind Germany's success is a range of factors only some of which can be controlled thus limiting the scope for the transfer of lessons to future sports mega-events. These factors included coordinated campaigns to raise awareness of Germany and the sports mega-event, the 'fan-centred' approach adopted by the Germans, and the uncharacteristically good weather enjoyed throughout the four weeks of the tournament. The factors over which the hosts had more control are discussed below.

Part of the so-called 'World Cup Hosting Strategy' (Federal Government 2006b, 10) was a long-term, carefully planned campaign to improve Germany's image abroad. If the outpouring of national sentiment among flag-waving Germans at the FIFA World Cup in 2006 was spontaneous, the strategy to enhance Germany's image was anything but. The thoroughly planned, coordinated and implemented strategy to change the national 'image' of Germany among foreign publics began well before the event itself and continued throughout and beyond. ${ }^{10}$ Well-orchestrated and resourced national and international campaigns were organised, funded, in the main, by the federal government, but designed in conjunction with partners from business (entitled 'Welcome to Germany: Land of Ideas'), FIFA and the German Football Association (entitled 'A time to make friends'). A number of campaigns were specifically designed to prepare Germany and the Germans to be hospitable to the crowds of foreign visitors that were expected for the competition (see also Kersting 2007, 282; Brauer and Brauer 2008). ${ }^{11}$

Taken together these campaigns added up to a concerted effort to leverage the benefits of a sports megaevent in terms of national image and economic gains: individually, however, they represent slightly different messages aimed at different audiences (FMI 2006, 31). For example, the service sector was targeted by 'The Nation-wide Service and Hospitality Campaign' (Federal Government 2006b, 87), which published brochures containing guidelines on how to deal with foreign visitors and which ran nationwide workshops to train and offer advice to 'service ambassadors' on intercultural relations, tolerance and foreign languages (Florek et al. 2008, 210). The 'Welcome to Germany: Land of Ideas' campaign, designed to improve the German national image by showcasing Germany and attracting tourism and foreign investment, was so successful that it continues to this day. It brought together key actors from business, science and culture, and facilitated the promotion of Germany's image externally. Such an image is made up of a wide variety of factors, which were cleverly brought together under the simple slogan of 'Land of Ideas', a phrase made prominent by the in-coming Federal president, Horst Köhler, in 2004, who suggested Germany should become more than the land of 'poets and thinkers' and more than just 'made in Germany' (Köhler 2004; Interview with Ariane Dirks). ${ }^{12}$ Part of the success of this campaign was-and is - that it is non-partisan and does not belong to a particular company; it crosses party political

\footnotetext{
${ }^{9}$ It is unsurprising to note that Germany's image has improved substantially in Britain since 2006, in great part because of this international exchange in which previously held stereotypes came under strain once exposed to actual empirical experience.

1012 years prior to the 2006 World Cup, the German National Tourist Board, along with the German Football Federation launched a campaign (partly in the hope of winning the 2006 bid) which communicated Germany as 'Destination Germany' to ' 75 million internet users, in 25 million print products, on 5000 fact-finding tours and at around 1000 trade fairs' (FMI 2006, 32).

11 Other campaigns included 'You are Germany' (http://www.du-bist-deutschland.de) which set out to reinvigorate German self-confidence (see Kersting 2007, 281)

12 The word 'idea' has a resonance abroad and it is a concept under which many things can be subsumed (Interview with Dirks).
} 
lines and speaks to actors in business, science and culture alike. The central aim of the campaign was to make Germany attractive to foreign publics. According to the managing director of 'Land of Ideas', Ariane Derks, the campaign has:

... a very global aim: our aim is to cater for Germany's positive domestic and international image ... so that Germany is attractive as a Standort (economic location) ... so that we position ourselves positively politically ... so that we are (hopefully) more attractive to people who may wish to work in Germany ....

The term 'attractive' recurs in interviews with both Ms Derks and officials at Germany's Foreign Office. It is clear that the 'language' of Joseph Nye is well known and actively used: the World Cup was looked upon as a catalyst around which to galvanise efforts and promote Germany's 'soft power'.

A final campaign to note is the arts and culture programme that accompanied the World Cup. According to Florek et al. $(2008,200)$, tourism research reveals that the possibility of attending mega-events is enhanced, if the event has additional non-event attractions. This, along with the obvious draw of Germany's rich and varied historical and cultural heritage, probably contributed to the higher-thanexpected 2 million foreign visitors during the World Cup period. All of the campaigns discussed above add up to a comprehensive, long-term approach to leveraging the benefits of the sports mega-event in terms of image and economic gains. ${ }^{13}$ An official at the German Foreign Office pointed out that this 'coordinated effort' by a variety of government and non-governmental (private) actors was crucial to the event's success in 2006. He stated further that the German Government had made a long-term, deliberate investment in 'soft power'. In fact,

We spend almost a quarter of the whole budget for foreign policy onculture which is more than 700 million Euros ... this is the long-term promotion of 'soft power' ... we want to bring people together ... and sport is one part of this [promotion of Germany's culture] (Interview German Foreign Office).

Thus, long-term Governmental investment coupled with carefully planned campaigns to maximise the impact of the World Cup resulted in Germany being perceived abroad in a much better light than prior to the sports mega-event (Anholt-GfK Roper Index 2007). Long-term forward planning was coupled with a very efficient infrastructure. The German train system (Deutsche Bahn) was able to accommodate 'around 15 million additional passengers during the World Cup' (Federal Government 2006a, 44) without any significant disturbances to regular customers (FMI 2006, 5). Some 3.7 million Euros were invested prior to the World Cup in improving rail and road infrastructure (FMI 2006, 5), a system that was already in a better state than those in most advanced capitalist countries (Interview with Gerhard Pfeil).

\section{What Does it Mean for Germany?}

It would appear that the German 'flair for organisation' (Interview German Foreign Office), long-term preparation, carefully planned campaigns, efficient infrastructure, football's dominance as the world's most popular sport, the fact that the 'majority of the population were behind the event' (Interview with Robert Ide) and the fine weather led to the successful projection of a positive image of Germany's image abroad. The question remains, however, of what this means for Germany? The mechanism whereby soft power is turned into influence on the world stage or whereby an enhanced reputation of a country yields concrete benefits is unclear. Interviewee 6 spoke of the manner in which he is personally treated by foreigners when abroad and how this has changed positively since 2006. On the national level, Nye speaks rather cryptically of the 'enabling conditions' that alter in the favour of the state yielding 'soft power' $(2004 ; 2008,101)$, thus, presumably allowing a state to articulate their national interests, gain the ear of key partners on the international stage and appear more attractive to other states.

${ }^{13}$ For a more in-depth discussion on image leveraging by Germany at the 2006 World Cup and the mechanisms they used, see Grix 2013. 
While national pride before and after the World Cup among Germans remained almost constant $(71 \%$ before the event and $72 \%$ afterwards felt 'very' or 'fairly proud' of their country), the biggest spike came during the event (78\%; Allbus cited in Kersting 2007, 284). How is it then that the domestic 'feelgood factor' can return to a similar level to that prior to the event yet the international image of a state can change? Herein lies one of the problems of measuring the difficult to measure. Confidence and patriotism can grow among a population, but Germans are still hesitant when asked about pride in their country. External actors' perceptions of Germany, on the other hand, seem to have been strongly affected by the 2006 World Cup. The New York Times sums up this sentiment when it suggested that the:

... preconceptions about Germany-its dullness, its love of order, its formality, its lack of exuberance-were perhaps the biggest casualties of a tournament played in a festive spirit, and marked by freewheeling generosity and the fruition of an often-painful German search for a patriotism at once natural and unthreatening. ${ }^{14}$

It is this change in others' perception of Germany that is seen as a success and the result of yielding 'soft power'.

${ }^{14}$ New York Times 9 July 2006. Available online at: http://query.nytimes.com/gst/fullpage.html?res=9A04E3D81030F93AA35754C0A9609C8B63\&pagewanted=all (Accessed 6 July 2011). 